\title{
AMCP Partnership Forum: Principles for Sound Pharmacy and Therapeutics (P\&T) Committee Practices: What's Next?
}

\begin{abstract}
SUMMARY
It has been nearly 20 years since the Academy of Managed Care Pharmacy

(AMCP) and other stakeholders adopted the Principles for a Sound Formulary System. Since that time, best practices for pharmacy and therapeutics (P\&T) committees have matured throughout the health care system.

On March 28, 2019, AMCP convened a group of thought leaders representing clinicians, academia, patient advocacy, payer organizations, and the pharmaceutical industry to consider P\&T committee best practices in today's evolving health care system. Specifically, the group provided perspectives on (a) P\&T committee composition and relevant stakeholders, (b) evaluation of emerging evidence for formulary decisions and recommendations around training of P\&T committee members, and (c) characteristics and best practices of successful committees.
\end{abstract}

J Manag Care Spec Pharm. 2020;26(1):48-53

Copyright $\odot 2020$, Academy of Managed Care Pharmacy. All rights reserved.

$\mathrm{T}$ he formulary system, when properly designed and implemented, can promote rational, clinically appropriate, safe, and cost-effective drug therapy. The pharmacy $\&$ therapeutics (P\&T) committee is responsible for developing, managing, updating, and administering the drug formulary system for a managed care organization (MCO) or hospital. ${ }^{1}$ The informed decisions that stem from the P\&T committee's scientific assessment of products allow organizations to ensure that all patients have access to needed medications while also remaining good stewards of limited health care dollars. Over the years, P\&T committees have become a common fixture across the health care spectrum, including in Medicare Part D programs, health insurance marketplace plans, commercial health plans, Medicaid programs, and other public payers., ${ }^{2,3}$ However, as health care dynamics change, it is important to advance P\&T committee best practices to meet the future needs of population health decision making.

To address these issues, the Academy of Managed Care Pharmacy (AMCP) convened a forum on March 28, 2019, at the AMCP Annual Meeting in San Diego, CA. With a goal of gathering stakeholder input, forum participants provided their perspectives on (a) P\&T committee composition and relevant stakeholders, (b) evaluation of emerging evidence for formulary decisions and recommendations around training of P\&T committee members, and (c) characteristics and best practices of successful committees.

P\&T Committees: Composition and Relevant Stakeholders MCOs vary in size, type of population covered, and reimbursement approaches across the different types of health systems nationwide. Within health systems, the central role of the P\&T committee is to objectively appraise, evaluate, and select drugs for the formulary. ${ }^{1-4}$

In addition to this core responsibility, P\&T committees establish policies and procedures to educate and inform health care providers about drug products, usage, and committee decisions. P\&T committees may also help support adoption of appropriate medication therapies through the development of clinical care plans, treatment guidelines, critical pathways, quality improvement programs that employ drug use evaluation, and disease management protocols. ${ }^{1}$ As an overview, a typical P\&T committee review process is described in Figure 1.

A P\&T committee is usually composed of actively practicing physicians, pharmacists, and other health care professionals, ${ }^{5-7}$ but forum participants added that a well-structured committee also includes members with the following roles and/or expertise:

Organizational Roles

- Administration

- Health economics and outcomes research (HEOR)/ pharmacoeconomist

- Leadership, chair, or department lead

- Nursing lead

- Patient representation

Expertise

- Medication use processes

- Safety and quality improvement

- Specific clinical specialties, as needed (e.g., oncology and pediatric endocrinology)

Generally, P\&T committee members with clinical backgrounds provide guidance on standards of care and usual treatment approach. Having a variety of perspectives and expertise is crucial to ensuring that the review of evidence for formulary decisions is conducted in an unbiased manner and is inclusive of relevant stakeholder perspectives. In the case of Medicare programs, the Centers for Medicare \& Medicaid Services require at least 1 independent practicing physician and 1 independent practicing pharmacist who are "independent and free of conflict" and do not have any financial arrangements with pharmacy benefit managers, drug companies, or other entities with vested interests. ${ }^{8}$ The inclusion of the patient perspective can also be a helpful component of the formulary evaluation process, since it provides additional insight into the practical use of therapies and effect on quality of life outcomes.

In addition, forum participants noted that continuous quality improvement is an important best practice of P\&T committees and that periodic review and reassessment of therapeutic categories should be part of standard operating procedure. This 


\section{FIGURE 1 Example of a Typical P\&T Process Overview ${ }^{5-7}$}

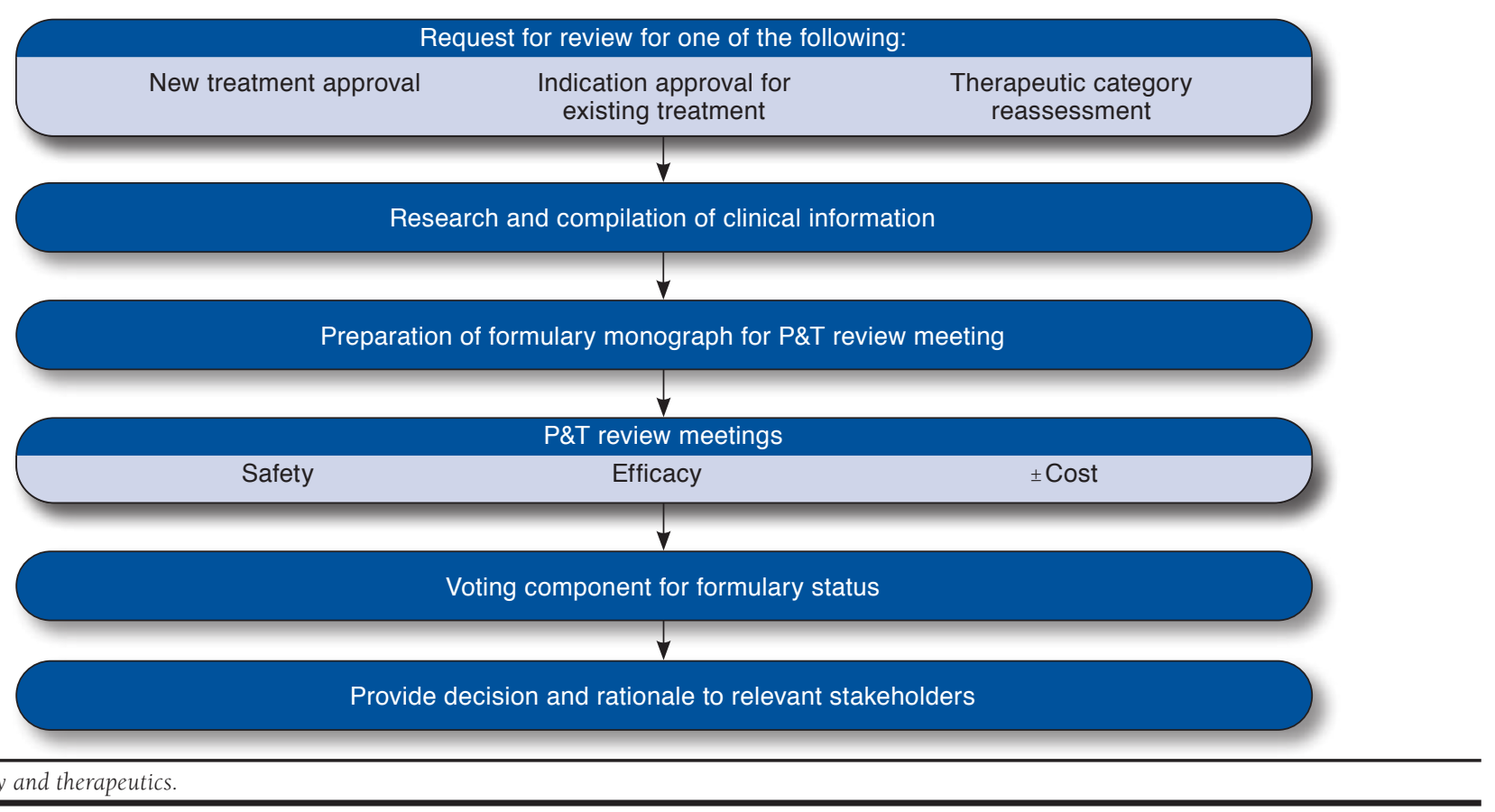

periodic review is also required for health plan accreditation by the Utilization Review Accreditation Commission and the National Committee for Quality Assurance., ${ }^{910}$

\section{P\&T Committees: Evaluation of Evidence and Training Recommendations}

One of the first and most important steps in the formulary review process is the research and assessment of available literature to support the creation of an objective formulary monograph before the P\&T committee meeting. The types of information that may be used to support P\&T discussions include published randomized controlled trials (RCTs), metaanalyses, treatment guidelines, manufacturer dossiers, and internal organization datasets.

Forum participants discussed findings from the SPEC Database, ${ }^{11}$ which helped provide background information on the type and frequency of information used by MCOs to make formulary decisions. This database was sourced from 17 payers, representing 130 million covered lives, and contains information on over 6,000 U.S. commercial health plan coverage policies for specialty drugs. A review of the SPEC Database found that RCTs and clinical guidelines were most commonly cited across payers as driving formulary decisions. However, many other types of studies, including economic evaluations and health technology assessments, were also noted to be relevant in making coverage decisions. Another takeaway was that the frequency of use for information types varied across therapeutic categories. For example, there was greater use of treatment guidelines for oncology therapies, and supportive clinical studies and guidelines were cited most frequently in the review of orphan drugs. ${ }^{11}$

The availability of real-world evidence for use by P\&T committees provides an additional set of data for review during the formulary evaluation process. The SPEC Database noted a currently low use of real-world evidence in formulary decisions, which participants attributed to the wide variations in type and quality of data collected across institutions. The availability of real-world evidence is generally limited at the time of initial drug review. As such, real-world evidence will likely provide more value later in the drug product lifecycle and be used to support updates to formulary status.

Forum participants also discussed the value of incorporating patient perspectives in making coverage decisions. Patients are directly affected by P\&T committee decisions, but because of several factors, such as varying levels of health literacy among patients, there are differences in how MCOs include the patient voice in P\&T committees and population health decisions. Although the current representation of patient perspectives on P\&T committees is thought to be limited, participants agreed that including the patient voice in formulary decisions should be a key objective moving forward. It was suggested that MCOs consider working with patient advocacy groups to help connect them with patient communities and work toward a greater understanding of the value of different treatments and medications for patients. 


\section{TABLE 1 Principles and Best Practices for P\&T Committees}

Committee Composition and Meeting Logistics

The P\&T committee, composed of actively practicing physicians, pharmacists, and other health care professionals, is the mechanism for administering the formulary system, which includes developing and maintaining the formulary and establishing and implementing policies on the use of drug products. ${ }^{2}$

Best practices for the PET committee:

- Include a broad range of member expertise (e.g., specific clinical specialties, medication use processes, safety, and quality improvement) to provide unique perspectives

- Designate specific roles to be included in the P\&T committee (e.g., administration, HEOR, chair or department lead, nursing lead, and patient representation)

- Align on a clear working definition of value for the P\&T committee

- Maintain objectivity within the P\&T committee, holding each member accountable in the decision-making process

- Standardize and formalize P\&T committee processes

- Develop protocols around anonymous voting and confidentiality for the P\&T process

- Provide administrative time for data/monograph review before meetings and ample time during the P\&T meeting for review and discussion Evidentiary Considerations

Formulary system decisions are based on scientific and economic considerations that achieve appropriate, safe, and cost-effective drug therapy. ${ }^{2}$

Consider or include the following types of evidence in reviews:

- Randomized clinical trials, making sure to assess the study design and results objectively

- Real-world data, to provide additional context in coverage decision reassessments and formulary updates

- Cost-effectiveness research and modeling, to assess the value of a therapy

- Patient perspectives, to provide insight into the practical use of therapies and effect on quality of life outcomes

- Expert opinions and reports from external organizations are helpful for reevaluations, new indications, and instances where limited data are available

\section{Training and Education}

The formulary system should include educational programs for payers, practitioners, and patients concerning their roles and responsibilities. ${ }^{2}$ Consider building educational programs to support the competencies of new stakeholders.

Provide training to all committee members and staff on the following:

- How to develop and present fair and relevant information in an accessible manner

- Methods, benefits, and limitations of various types of research approaches such as health technology assessments, cost-effectiveness research, and economic evaluations

- Clinical data interpretation skills

- Value and cost-benefit assessments

$P E T=$ pharmacy and therapeutics; HEOR= health economics and outcomes research

Other sources of information increasingly being used by $P \& T$ committees include reports from external groups or expert opinion publications, value frameworks, clinical practice guidelines, and reports from patient advocacy groups that help provide a clinical, economic, and humanistic perspective to each formulary decision.

Participants also noted that the formulary monograph content should be presented as neutral and objective so that clinical decisions are based on the strength of scientific evidence and standards of practice. In addition, listing the pros and cons of the therapy being discussed from clinical, economic, and societal perspectives were seen as a sound way to ensure that formulary system decisions are based on a thorough evaluation of the benefits, risks, and potential outcomes for patients.

The availability of evidence such as real-world evidence, value framework reports, and patient-reported outcomes bring new data points for P\&T decision making. There is a recognized need for training regarding these newer resources so that P\&T committees can fully recognize and use their value. Furthermore, P\&T committees would benefit from developing standardized mechanisms to incorporate emerging datasets into formulary evaluation processes.

\section{Characteristics and Best Practices of Successful P\&T Committees}

Several themes emerged around the characteristics of successful P\&T committees, with a key emphasis on the importance of delivering patient-centric care. Best practice recommendations ranged from current thoughts on the composition of the committee and logistics, to approaches to dataset consideration, and finally, proactive suggestions on training needs for future committee members and stakeholders as described in Table 1.

Three contemporary issues encountered by P\&T committees were highlighted. 


\section{Disclosing and Managing Potential Conflicts of Interest Within P\&T Committees}

The formulary system must have its own policies or adhere to other organizational policies that address conflicts of interest (COIs) and disclosure by P\&T committee members. ${ }^{2}$ Forum participants noted that the first step in managing COIs is to define the scope of COIs within the organization. Often, COIs are financial in nature, such as having a direct financial stake in a company, but modern COIs may need to have several layers of complexity, since member activities can change over time. As an example, a P\&T committee member may not initially have any immediate financial links to a manufacturer but may be later contract to speak on behalf of a manufacturer. Members may also have a family member or friend with ties to a manufacturer, which could be a COI that affects the committee member's impartiality in decision making. To provide objectivity and impartiality to P\&T decisions, it is important to set clear definitions and policies for COIs and hold all voting members to the same level of accountability.

The most important part of COI management is using a formalized process to identify, document, and monitor COIs of P\&T committee members. One option is to require a standardized disclosure form from all members. On this form, financial relationships, financial holdings, or personal relationships with organizations that have a product with potential formulary conflicts should be disclosed. Participants also noted that disclosures should be made for a specific period of time (e.g., in the last 12 months) and regularly assessed (e.g., annually). Once the information has been disclosed, the committee chair, or a group of executive members, could evaluate the COIs. Depending on the effect of COIs on specific decisions, the knowledge and value of the P\&T committee member can be assessed, and different levels of controls can be enacted, ranging from recusal from the specific discussion, recusal from the vote, or dismissal from the committee for the time frame for which the COI is relevant. In addition, committees may consider the inclusion of someone that can take on the role of a compliance monitor in P\&T committee meetings to ensure that policies and protocols are followed.

\section{Communicating Formulary Decisions to External Entities}

The MCO or hospital should inform physicians, pharmacists, other health care professionals, patients, and payers about the factors that affect formulary system decisions, including cost containment measures, the procedures for obtaining nonformulary drugs, and the importance of formulary compliance to improving quality of care and restraining health care costs. ${ }^{2}$ Because of the confidentiality of P\&T committee meetings, however, external stakeholders may have limited information about how formulary decisions are made. To build stakeholder confidence and support for formulary decisions, it is important that P\&T committees establish policies and procedures to educate and inform health care providers and the interested public about drug products, usage, and committee decisions.

Forum participants emphasized that a way to ensure appropriate communication of formulary decisions is to include communication expectations and standards in the annual compliance training documents for P\&T committee members. Compliance training should cover federal and corporate regulations that each committee member must follow and ensure that the decision-making process is consistent across therapies. This allows MCOs and hospital organizations to better communicate their formulary decision-making approach.

Forum participants also suggested that there be a minimum level of information communicated, written at a language level accessible to most patients (e.g., fifth- or sixth-grade reading level) and clearly summarize the evidence reviewed by the committee in making its decisions. Several participants noted that study citations do not need to be included in all stakeholder communications.

The following additional methods of improving transparency around formulary decisions were also discussed:

- Providing information about the type and relationship of experts that are members of, or consultants to, the P\&T committee.

- Listing an overview of rules and mandates followed during the P\&T processes.

- Noting if/when conflict of interest procedures were implemented.

- Sharing information on the logistical processes of P\&T meetings.

In the discussions between forum participants, the amount of information that the participants felt was necessary to include in formulary rationale documents varied, but the key takeaway was that the level of detail for formulary decisions shared should be at the discretion of the institution. However, as a general rule, participants proposed that the rationale documentation should be updated with each reassessment.

\section{Ensuring Inclusion and Representation to Cover Clinical, Economic, and Patient Perspectives in P\&T Committees}

As described in Table 1, key stakeholders of the P\&T committee represent various perspectives, including clinicians, pharmacoeconomists, administrators, patient representatives, and quality improvement managers. However, forum participants acknowledged that it is not always logistically feasible to have representation from all stakeholders at every P\&T committee meeting. As such, they suggested that processes should be established to bring in various perspectives for consideration at relevant points during the P\&T review process.

The P\&T committee chair has an important leadership role and should be capable of facilitating engagement of a variety of viewpoints during the meeting and also be accountable to ensure impartiality of the committee. 


\section{Conclusions}

As health care systems and new therapies continue to evolve, it will be important for P\&T committees to continuously evaluate their processes and discuss how new types of evidence and perspectives can help in the formulary decision-making process. The approach to formulary decisions and P\&T processes appropriately varies across institutions, based on policies and external market positions. Variation also exists in the guidelines and evidence cited by payers in publicly available coverage decisions across therapeutic classes and for the same drug-indication pair.

New information and data sources available for evaluating drugs and devices will likely require additional competencies in evaluation techniques and methodologies by P\&T committee members. Uniform training of P\&T committee members is also important and can include guidance on how evidence should be used and viewed, as well as outlining policies and protocols. P\&T committees would benefit from having members with strong data interpretation and clinical assessment abilities who can maintain objectivity in formulary decision making while considering all relevant stakeholder perspectives.

Furthermore, MCOs have an opportunity to engage and incorporate the patient perspective in the formulary process. This is an area that participants agreed could be improved across the majority of P\&T committees with the inclusion of patient perspectives in the formulary review.

Finally, establishing organizational policies on transparency around P\&T committee processes and decisions are crucial for establishing successful P\&T committees.

\section{Forum Participants}

DANIAL BAKER, Director, Drug Information Center, Washington State University College of Pharmacy and Pharmaceutical Sciences; CHRISTINA BARRINGTON, Vice President, Pharmacy Programs, Priority Health; ERIC CANNON, Vice President, Pharmacy Benefits, SelectHealth; JAMES CHAMBERS, Associate Professor, Tufts Medical Center; JOSEPH COPPOLA, Managing Director, Life Sciences, and Commercial and Market Access Practice Leader, Deloitte Consulting; RYAN COX, Vice President, Access Experience Team, Precision for Value; MICHAEL DILL, Associate Director, Market Access Strategy and Innovation, Novo Nordisk; LEE DING, Associate Director, Managed Care Liaison, Genentech; JULIE DITUCCI-REITER, Clinical Policy and Programs, Steward Health Choice; JENNIFER GRAFF, Vice President, Comparative Effectiveness Research, National Pharmaceutical Council; LARRY GREEN, Director, Pharmacy Affairs, Amgen; ESTAY GREENE, Vice President, Pharmacy Services, Blue Cross Blue Shield of North Carolina; CAROLYN HA, Director, Policy and Research, PhRMA; CONOR HANRAHAN, Director, Medication Policy, Outcomes, and Stewardship, Intermountain Healthcare; GEORGE JARESKO, Director, US Medical Value and Access Communications, Amgen; STEPHEN JUNG, Principal Pharmacist, Blue Shield of California;
MATTHEW LAU, Lead, Healthcare Insights and Solutions, Takeda; JEREMY LEE, Director, Drug Information, MedImpact; MANDY LEONARD, System Director, Drug Use Policy and Formulary Management, Cleveland Clinic; CRAIG MATTSON, Retired, Prime Therapeutics; LYNN NISHIDA, Vice President, WithMe Health; VINCENT PACILEO, Director, Federal Affairs, Arthritis Foundation; SWATI PATEL, Senior Manager, Deloitte Consulting; ANNE PUGH, Formulary Management, Kaiser Permanente; ALYNN PURDUM, Chief Compliance Officer, EnvisionRxOptions; KELLIE RADEMACHER, Vice President, Access Experience Team, Precision for Value; EILEEN SAKAI, Director, Drug Information Services and Outcomes Research, National Pharmacy Programs and Services, Kaiser Permanente; ELIZABETH SAMPSEL, Vice President, Payer Strategy and Relations, Dymaxium; IRIS TAM, Director, Outcomes Research and Quality of Care, Achaogen; DANIEL TJIOE, Regional Medical Affairs Director, Merck \& Co.; HAI TRAN, Associate Director, Drug Use Policy, Cedars-Sinai Medical Center; ROBIN TURPIN, Value Evidence Lead, Takeda; JOE VANDIGO, Director, Policy and Research, PhRMA; LAURIE WESOLOWICZ, Vice President, Clinical Programs and Services, Archimedes/EpiphanyRx; and ADAM WILSON, Senior Director, Formulary Management, MagellanRx Management.

CORRESPONDENCE: Cynthia Reilly, MS, BSPharm, Chief Operating Officer, Academy of Managed Care Pharmacy, 675 N. Washington, St., Ste. 220, Alexandria, VA 22314. Tel.: 703.684.2600; E-mail: creilly@amcp.org.

\section{DISCLOSURES}

This AMCP Partnership Forum and the development of the proceedings document were supported by Amgen, Genentech, Merck, National Pharmaceutical Council, Novo Nordisk, Pharmaceutical Research and Manufacturers of America, Precision for Value, and Takeda. This proceedings document presents common themes and comments from individuals participating in the forum and is not necessarily endorsed by all participants nor should it be construed to reflect group consensus.

Eric Jen, PharmD, and Cynthia Reilly, MS, BSPharm, declare no conflicts of interest, real or apparent, with any product or service mentioned in this article. Jen is an employee of Precision for Value, a sponsor of the Partnership Forum. Development of these proceedings was done as an in-kind sponsorship. Reilly is an employee of AMCP.

\section{ACKNOWLEDGMENTS}

The AMCP Partnership Forum "Principles for Sound Pharmacy and Therapeutics (P\&T) Practices: What's Next?" was moderated by Jeff Lee, PharmD, FCCP, Associate Dean for Academic Affairs at Lipscomb University. This proceedings report was prepared by Eric Jen, PharmD, Vice President of Clinical Services at Precision for Value, which receives financial support from pharmaceutical and other life science companies. This proceedings report was reviewed by Terry Richardson, PharmD, BCACP, Senior Pharmacist Consultant at AMCP.

\section{REFERENCES}

1. American Society of Health-System Pharmacists. ASHP Statement on the Pharmacy and Therapeutics Committee and the Formulary System. 2012. Available at: https://www.ashp.org/-/media/assets/policy-guidelines/docs/ statements/pharmacy-and-therapeutics-committee-and-formulary-system. ashx. Accessed December 4, 2019. 
2. Principles of a sound drug formulary system. In: Hawkins B, ed. Best Practices for Hospital and Health System Pharmacy: Positions and Guidance Documents of ASHP. Bethesda, MD: American Society of Health-System Pharmacists; 2011.

3. American Society of Health-System Pharmacists. Principles of a sound drug formulary system. June 4, 2000. Available at: https://www.ashp.org/-/ media/assets/policy-guidelines/docs/endorsed-documents/endorsed-documents-principles-sound-drug-formulary-system.ashx. Accessed December 4, 2019

4. Tyler LS, Cole SW, May JR, et al. ASHP guidelines on the pharmacy and therapeutics committee and the formulary system. Am J Health Syst Pharm. 2008;65(13):1272-83.

5. Navarro R. Managed Care Pharmacy Practice. 2d ed. Sudbury, MA: Jones and Bartlett Publishers; 2009.

6. Mannebach MA, Ascione FJ, Gaither CA, et al. Activities, functions, and structure of pharmacy and therapeutics committees in large teaching hospitals. Am J Health Syst Pharm. 1999;56(7):622-28.
7. Centers for Medicare \& Medicaid Services. Medicare Prescription Drug Benefit Manual. Available at: https://www.cms.gov/Medicare/PrescriptionDrug-Coverage/PrescriptionDrugCovContra/PartDManuals. Accessed December 11, 2019.

8. Centers for Medicare \& Medicaid Services. Medicare program; contract year 2016 policy and technical changes to the Medicare Advantage and the Medicare Prescription Drug Benefit programs. Fed Regist. 2015;80(29):7912-66. Available at: https://www.govinfo.gov/content/pkg/FR-2015-02-12/pdf/201502671.pdf. Accessed December 11, 2019.

9. Utilization Review Accreditation Commission. Health Plan Accreditation Guide. Version 7.3. Available at: https://www.urac.org/sites/default/files/standards_measures/pdf/STDGlance_HealthPlan3_0.pdf. Accessed December 4, 2019.

10. National Committee for Quality Assurance. Health plan accreditation updates 2020 overview. 2018. Available at: https://www.ncqa.org/wp-content/uploads/2018/11/20181102_Health_Plan_Accreditation_HPA_2020_ Updates_Overview.pdf. Accessed December 4, 2019.

11. Center for the Evaluation of Value and Risk in Health. SPEC Database. 2018. Available at: https://cevr.tuftsmedicalcenter.org/databases/spec-database. Accessed December 4, 2019. 